\title{
KAJIAN KERENTANAN BANGUNAN PASCA GEMPA LOMBOK 5 AGUSTUS 2018
}

\section{VULNERABILITY ASSESSMENT OF BUILDINGS AFTER LOMBOK EARTHQUAKE ON AUGUST 5, 2018}

\author{
Mulyo Harris Pradono ${ }^{1}$ \\ ${ }^{1}$ Pusat Teknologi Reduksi Risiko Bencana - TPSA - Badan Pengkajian dan Penerapan Teknologi, \\ Gedung 820, Geostech, Puspiptek, Tangerang 15314. Telepon: (021) 75791378 \\ e-mail: mulyo.harris@bppt.go.id
}

\begin{abstract}
On August 5, 2018 an M7.0 earthquake occurred on the mainland of Lombok Island with a depth of $10 \mathrm{~km}$. The earthquake caused significant damage to structures both houses and buildings. Among many damaged buildings there were mosques. The study herein is focused on the mosque buildings because they are used for public and have a specific structural characteristics. The mosques studied were those damaged but not collapsed, so that the data acquisition could be done practically, e.g., in the form of concrete compressive strength, dimension of reinforcement, and dimensions of structures (concrete beams, columns, and slabs). The data results were then inputted to the structural analysis program to build the structural model. The model was simulated by using earthquake loading so as to know at what seismic load the structure were damaged.
\end{abstract}

Keywords: Lombok earthquake, vulnerability, buildings, mosques

\begin{abstract}
ABSTRAK
Pada tanggal 5 Agustus 2018 terjadi gempa dengan kekuatan M7,0 di daratan Pulau Lombok dengan kedalaman $10 \mathrm{~km}$. Gempa menimbulkan kerusakan yang signifikan pada bangunan-bangunan baik bangunan rumah maupun gedung. Salah satu bangunan yang banyak rusak adalah masjid. Karena masjid merupakan bangunan yang digunakan untuk umum dan memiliki karakteriktik struktur yang khas, maka kajian dipusatkan pada bangunan masjid. Masjid-masjid yang dikaji mengalami kerusakan tapi tidak runtuh, sehingga perolehan data dapat dilakukan misalnya berupa kuat tekan beton, dimensi tulangan, dan dimensi struktur (balok, kolom, dan pelat beton). Hasil datanya kemudian dimasukkan dalam program analisis struktur untuk mendapatkan model struktur dan pada model tersebut kemudian dilakukan simulasi beban gempa agar diketahui pada beban gempa berapa struktur mengalami kerusakan.
\end{abstract}

Kata kunci: gempa Lombok, kerentanan, bangunan, masjid

\section{PENDAHULUAN}

\subsection{Latar Belakang}

Pulau Lombok mengalami rangkaian gempa dimulai pada tanggal 29 July 2018 (M6.4) sebagai foreshock, 5 August 2018 (M7.0) sebagai mainshock pertama, 9 Agustus 2018 (M6.2) sebagai aftershock signifikan, serta 19 Agustus 2018 yang didahului foreshock M6.3 dan mainshock kedua M6.9 sepuluh jam setelahnya. Wilayah Lombok, Provinsi Nusa Tenggara Barat (NTB), terletak pada kawasan tektonik aktif, dimana menurut buku Sumber dan Bahaya Gempa Nasional 2017, Pulau Lombok dikelilingi oleh beberapa sumber gempa, yaitu diantaranya Zona Back Arc Thrust di wilayah utara, megathrust di selatan, dan sistem sesar geser di sisi barat dan timurnya. Lokasi mainshock gempa 5 August 2018 (M7.0) dan intensitas gempabuminya diperlihatkan pada Gambar 1.

Dari gambar tampak bahwa intensitas gempa dapat mencapai MMI VIII pada beberapa lokasi, terutama Lombok Barat Laut. Ini menunjukkan intensitas yang sangat merusak. 


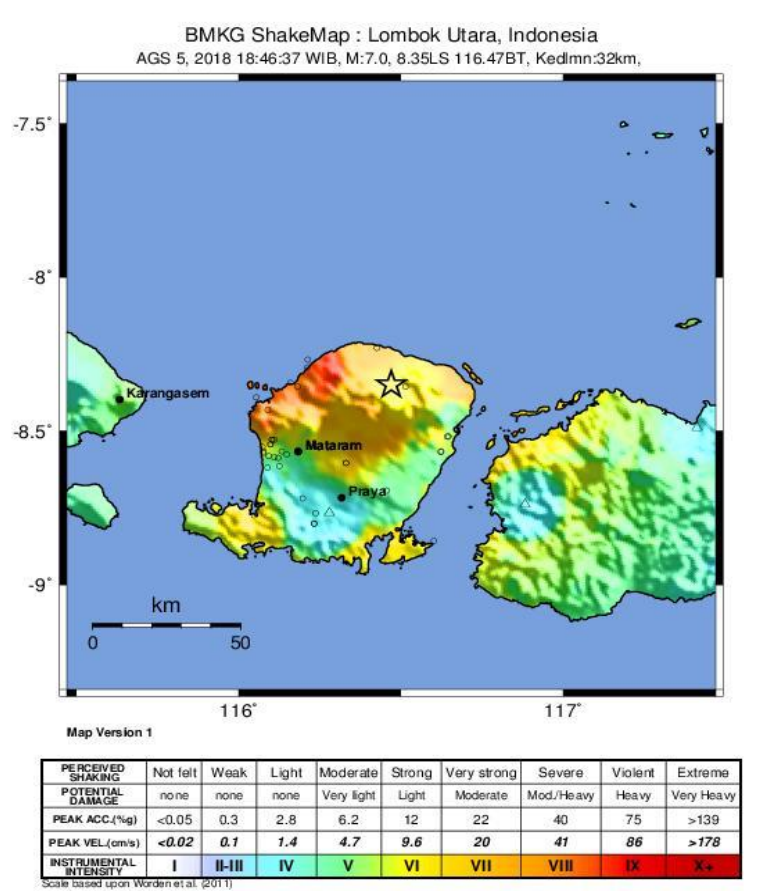

Gambar 1. Lokasi Mainshock Tanggal 5 Agustus 2018 (M7.0) dan intensitas gempabumi (Sumber: BMKG Shakemap, $\mathrm{BMKG)}$

Pada tanggal 7 sampai dengan 10 Agustus 2018, penulis diberangkatkan oleh Pusat Teknologi Reduksi Risiko Bencana BPPT untuk melakukan kaji cepat mengenai kerentanan bangunan di Pulau Lombok. Salah satu bangunan yang banyak rusak adalah masjid. Karena masjid merupakan bangunan yang digunakan untuk umum dan memiliki karakteriktik struktur yang khas, maka kajian dipusatkan pada bangunan masjid. Masjidmasjid yang dikaji mengalami kerusakan tapi tidak runtuh, sehingga perolehan data dapat dilakukan misalnya berupa kuat tekan beton, dimensi tulangan, dan dimensi struktur (balok, kolom, dan pelat beton). Hasil datanya kemudian dimasukkan dalam program analisis struktur untuk mendapatkan model struktur dan pada model tersebut kemudian dilakukan simulasi beban gempa agar diketahui pada beban gempa berapa struktur mengalami kerusakan.

Metoda kajian pada struktur yang sudah berdiri sudah banyak diterapkan oleh para peneliti. Setiawan dan Imran dalam makalahnya menyatakan (Setiawan dan Imran, 2014) bahwa untuk bangunan bertingkat tinggi, pengaruh batasan geser dasar minimum menyebabkan desain bangunan menjadi lebih kaku dikarenakan gaya gempa yang dianalisa menjadi jauh lebih besar dibandingkan dengan desain tanpa memperhitungkan geser dasar minimum. Dengan demikian untuk bangunan bertingkat tinggi, analisis tanpa memperhitungkan batasan geser dasar minimum dapat membahayakan.

Aribisma et al. (2015) menyatakan bahwa, berdasarkan hasil kajiannya pada gedung 12 lantai, maka untuk beberapa bagian yang mengalami kegagalan, diperlukan perkuatan pada bagian tersebut, kemudian dilakukan pengecekan ulang dengan analisa pushover untuk mengetahui apakah struktur mencapai tingkat keamanan yang diinginkan. Metoda perkuatan dapat menggunakan CRFP (Carbon Reinforced Fiber Polymer) karena pengerjaan menggunakan CRFP relatif lebih mudah, cepat, dan dapat mengantisipasi kegagalan geser maupun lentur.

Rizky et.al. (2015) menyatakan bahwa kajian kekuatan gedung yang terdiri atas tower 16 lantai dan podium 5 lantai menunjukkan hasil yang berbeda jika menggunakan beban gempa statik ekivalen, beban gempa respon spektrum, atau beban gempa riwayat waktu. Oleh sebab itu diperlukan beberapa jenis beban gempa untuk mengkaji sebuah gedung.

\subsection{Tujuan Penelitian}

Tujuan dari penelitian ini adalah untuk mengetahui mekanisme kerusakan pada bangunan yang ditinjau dan pada kekuatan MMI berapa bangunan mulai rusak. Apabila bangunan ini akan diperbaiki, maka metoda apa yang sesuai untuk peningkatan kekuatannya.

\section{BAHAN DAN METODE}

\subsection{Bahan} adalah:

Data yang diperlukan dalam penelitian ini

- data dimensi tulangan di dalam beton (Sesuai dengan "Tatacara pengukuran ketebalan selimut beton dengan covermeter elektromagnetik", 2015)

- data kuat tekan beton (sesuai SNI 03-44301997)

- data dimensi struktur beton (diukur dengan laser distometer dan meteran)

- data beban tambahan (sesuai SNI 1727:2012)

\subsection{Metode}

Setelah data di atas diperoleh untuk empat masjid yang ditinjau (disajikan dalam makalah ini hanya satu masjid yang mewakili), maka 
selanjutnya dilakukan analisis menggunakan perangkat lunak program analisis struktur:

- analisis beban gempa pada struktur (dengan SNI 1726:2012)

- analisis kapasitas struktur (dengan SNI 2847:2013)

- analisis kerentanan struktur (dengan program analisis struktur)

- analisis metode perkuatan struktur (dengan program analisis struktur).

Metoda analisis kapasitas struktur dengan SNI 2847:2013 pada prinsipnya adalah jumlah kekuatan lentur nominal kolom yang merangka ke dalam suatu joint, harus minimal $6 / 5$ kali jumlah kekuatan lentur nominal balok yang merangka ke dalam joint yang sama. Dengan kata lain, hal ini adalah untuk memastikan bahwa pada saat terjadi gempa besar, kerusakan pada kolom hanya terjadi di ujung kolom terbawah, dan pada balok-baloknyanya. Dengan kata lain, mekanisme strong-column-weak-beam dapat dicapai, yang dapat menjamin bangunan tidak runtuh saat terjadi gempa. Hal inilah yang perlu dipastikan pada setiap gedung yang dikaji.

\section{HASIL DAN PEMBAHASAN}

\subsection{Hasil}

\subsubsection{Hasil Pengukuran di Lapangan}

Masjid Kerandangan terletak di Jl. Raya

Senggigi No. 16, Senggigi, Batu Layar, Kabupaten Lombok Barat, Nusa Tenggara Barat 83355 (Koordinat: -8.4872830 , 116.0392760). Masjid ini terdiri dari satu lantai dengan kubah di atasnya. Masjid dibuat dari konstruksi rangka beton bertulang, dengan sekat antar ruangan berupa tembok bata sebagian. Masjid selesai dibangun pada tahun 2014.

Pola kerusakan yang terjadi pada bangunan adalah rusaknya kolom-kolom masjid, sehingga terjadi sendi plastis baik di ujung bawah kolom maupun di ujung atas kolom. Pola kerusakan seperti ini berpotensi terjadinya soft story pada lantai ini. Seharusnya pola kerusakan adalah di dasar kolom saja dan di balok-baloknya, yang sering disebut sebagai strong column weak beam.

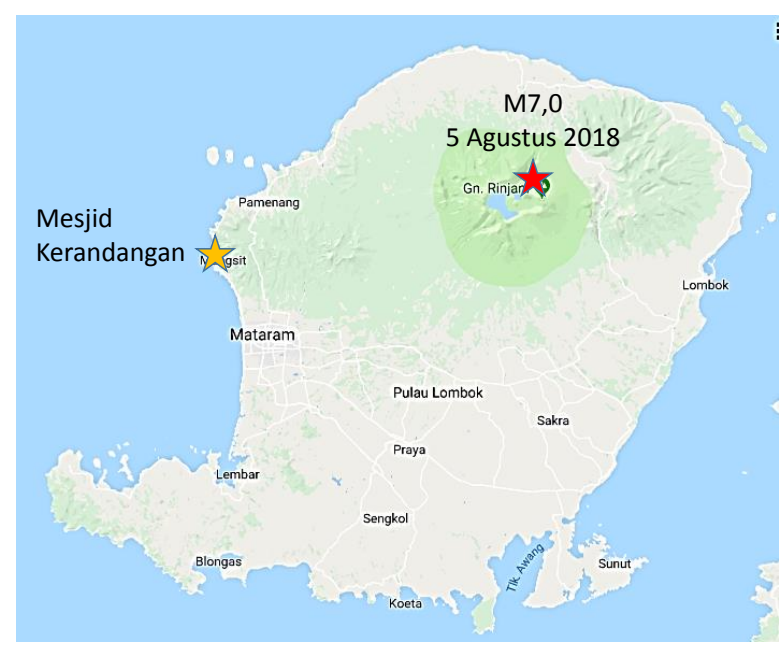

Gambar 2. Lokasi Masjid Kerandangan dan Lokasi Episenter (Sumber Lokasi Episenter: $\mathrm{BMKG})$

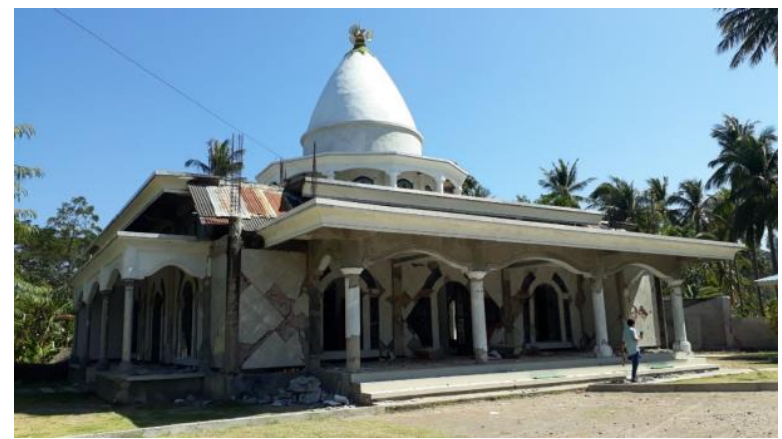

Gambar 3. Struktur Bangunan Masjid Kerandangan

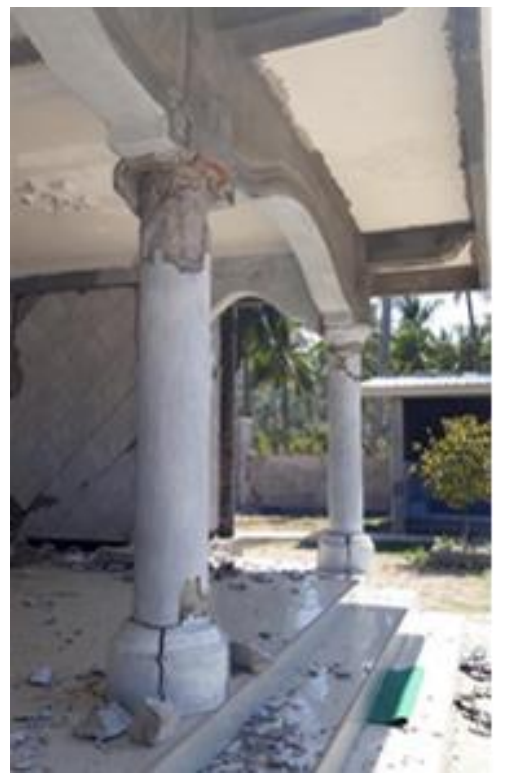

Gambar 4. Pola Kerusakan yang Terjadi pada Bangunan adalah Rusaknya KolomKolom 


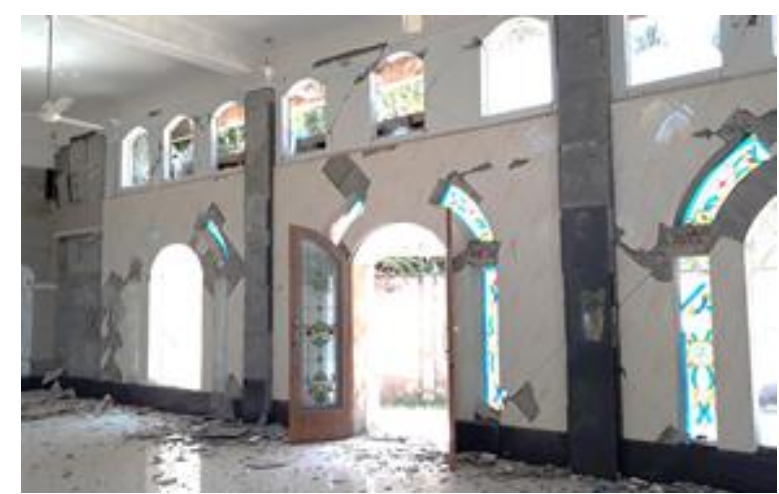

Gambar 5. Deformasi yang Besar Saat Terjadi Gempa Menyebabkan Kerusakan pada Komponen Non Struktural yang Dapat Membahayakan

Walaupun akhirnya bangunan ini tidak runtuh, akan tetapi karena deformasi yang besar saat terjadi gempa, maka kerusakan pada komponen non struktural (tembok bata, kaca jendela, dan keramik dinding) cukup membahayakan bagi manusia karena dapat melukai.

Pada kolom beton yang terkelupas lapisan plesterannya, maka dapat dilakukan uji Hammer Test pada beton aslinya. Tujuannya adalah untuk memperoleh kuat tekan beton pada kolom yang ditinjau. Uji Hammer Test dilakukan pada beberapa kolom yang tampak beton aslinya. Hasilnya ditunjukkan pada tabel berikut. Hasil ini cukup rendah mengingat untuk bangunan seperti masjid ini maka kuat tekan betonnya paling tidak adalah $25 \mathrm{MPa}$.

Tabel 1. Hasil Kuat Tekan Beton Kolom

\begin{tabular}{c|c|c|c|c}
\hline No & $\begin{array}{c}\text { Koordinat } \\
\text { Kolom }\end{array}$ & $\begin{array}{c}\text { Tipe } \\
\text { Kolom }\end{array}$ & Bentuk & $\begin{array}{c}\text { Kuat Tekan } \\
\text { Beton } \\
(\mathrm{MPa})^{*}\end{array}$ \\
\hline 1 & B2 & K1 & Bundar & 10,5 \\
\hline 2 & A2 & K1 & Bundar & 10,5 \\
\hline 3 & C4 & K2 & Persegi & 6,0 \\
\hline 4 & B5 & K1 & Bundar & 9,5 \\
\hline
\end{tabular}

${ }^{\star}$ Ekivalen kuat tekan silinder beton

Pada ujung kolom yang rusak, bisa ditemukan tulangan kolomnya. Tulangan ini diukur diameternya dan dihitung jumlahnya. Hasilnya dapat dilihat pada Gambar 6. Kolom tipe 1, berbentuk bundar (Gambar 6.a) dengan diameter $30 \mathrm{~cm}$, tulangan $4 \times 14 \mathrm{~mm}$ dan $4 \times 10$ $\mathrm{mm}$ (tulangan tipe polos). Data selanjutnya adalah:

- Luas tulangan $14 \mathrm{~mm}=615 \mathrm{~mm} 2$

- Luas tulangan $10 \mathrm{~mm}=314 \mathrm{~mm} 2$

- Total luas: $=929 \mathrm{~mm} 2$

- Rasio tulangan $=929 /(3.14 \times 0,25 \times 300 \times$ $300)=0,013$ (mendekati 0,010 ; nilai minimum untuk penulangan kolom)
- Tulangan ekivalen: $=8 \times 12 \mathrm{~mm}$; Luas $=$ $904 \mathrm{~mm} 2$ (untuk analisis)

- Sengkang: 8 mm @ 15 cm
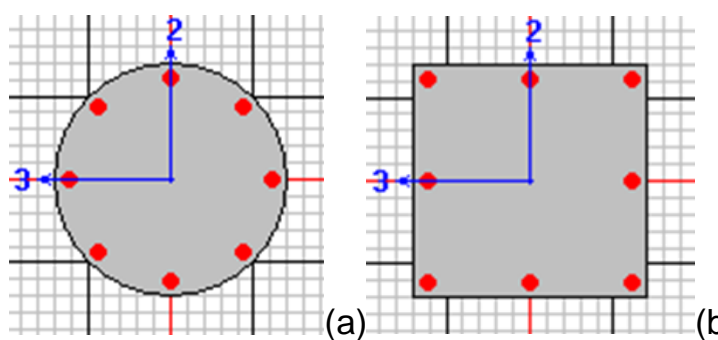

Gambar 6. Penampang Kolom dan

Tulangannya (Sumber: Hasil Pengukuran Lapangan)

Kolom tipe 2, berbentuk persegi (Gambar 6.b) dengan sisi $30 \mathrm{~cm}$, tulangan $4 \mathrm{x}$ $14 \mathrm{~mm}$ dan $4 \times 10 \mathrm{~mm}$ (tulangan tipe polos). Data selanjutnya adalah:

- Luas tulangan $14 \mathrm{~mm}=615 \mathrm{~mm} 2$

- Luas tulangan $10 \mathrm{~mm}=314 \mathrm{~mm} 2$

- Total luas: $=929 \mathrm{~mm} 2$

- Rasio tulangan $=929 /(300 \times 300)=0,01$ (nilai minimum untuk penulangan kolom)

- Tulangan ekivalen: $=8 \times 12 \mathrm{~mm}$; Luas $=$ 904 mm2 (untuk analisis)

- Sengkang: 8 mm @ 15 cm

Untuk balok dan pelat beton, karena posisi yang tinggi dan tidak memungkinkan untuk diukur langsung, maka digunakan atuanaturan baku untuk ukuran balok. Dari data balok tersebut tampak bahwa ada bagian balok $50 \mathrm{~cm} \times 25 \mathrm{~cm}$ yang ditumpu oleh kolom sebesar $30 \mathrm{~cm} \times 30 \mathrm{~cm}$. Hal ini berpotensi terjadinya fenomena strong beam weak column, yang berpotensi terjadinya keruntuhan apabila kapasitas kolomnya terlamapui.

- Balok untuk bentang 6 meter:

$\checkmark$ Tinggi: $\mathrm{h}=6 \mathrm{~m} / 12=50 \mathrm{~cm}$

$\checkmark \quad$ Lebar: $\mathrm{b}=\mathrm{h} / 2=25 \mathrm{~cm}$

- Balok untuk bentang 4 meter:

$\checkmark$ Tinggi: $\mathrm{h}=4 \mathrm{~m} / 12 \approx 35 \mathrm{~cm}$

$\checkmark \quad$ Lebar: $\mathrm{b}=\mathrm{h} / 2 \approx 15 \mathrm{~cm}$

- Pelat Lantai Atap dan Dome: $\mathrm{t}=12 \mathrm{~cm}$ 


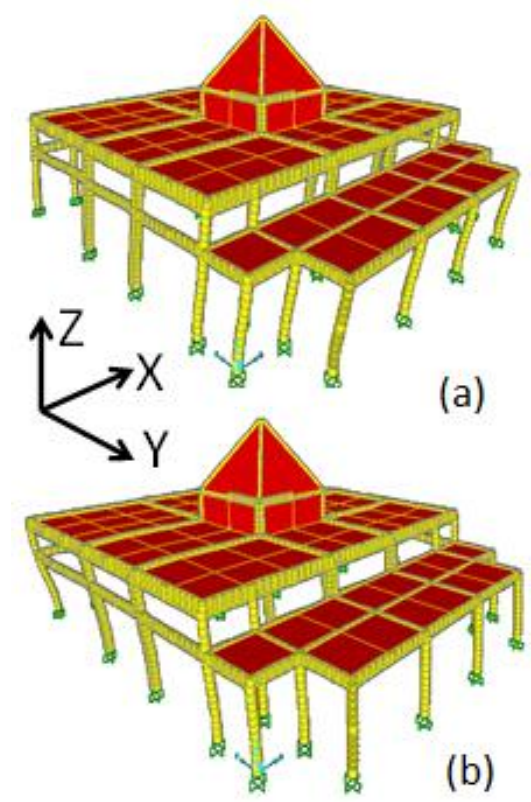

Gambar 7. Model Masjid dan Ragam Getarnya (Sumber: Hasil Analisis)

\subsubsection{Hasil Analisis}

Berdasarkan data-data di atas, maka dilakukan pemodelan terhadap struktur masjid tersebut. Hasilnya ditunjukkan pada Gambar 7. Gambar 7 a adalah ragam getar ke 1 dengan $T 1$ $=0,52372$ detik (arah $\mathrm{Y})$ dan ragam getar ke 2 dengan $T 2=0,52141$ detik (arah $X)$ (Gambar $6 b)$.

Beban gempa disimulasikan pada model di atas. Percepatan spektral sebesar $0,1 \mathrm{~g}$ dan $0,2 \mathrm{~g}(\mathrm{~g}=9,8 \mathrm{~m} /$ detik2; percepatan gravitasi) diaplikasikan pada model di atas pada arah X. Hasilnya menunjukkan bahwa pada saat percepatan spektral sebesar $0,1 \mathrm{~g}$ maka kolomkolom pada struktur masjid masih belum rusak, ditunjukkan dalam warna hijau dari hasil program analisis struktur (Gambar 8a). Sedangkan saat percepatan spectral dinaikkan menjadi 0,2g, maka kolom-kolom mulai rusak, ini ditunjukkan dengan warna merah pada kolom tersebut (Gambar 8b). Untuk simulasi gempa arah $Y$ juga memberikan hasil yang serupa.

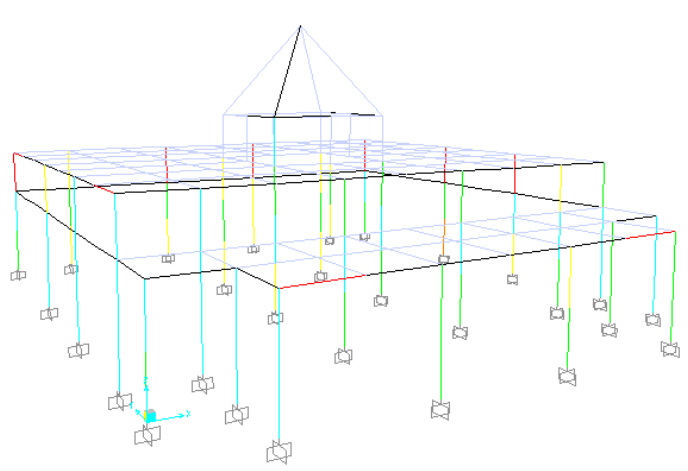

(a)

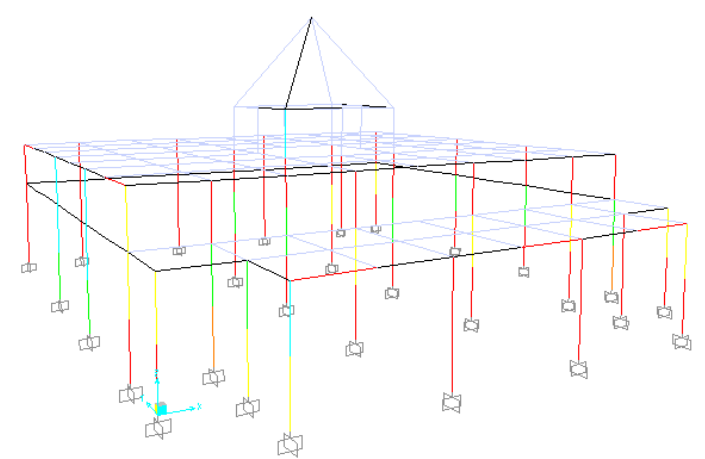

(b)

Gambar 8. Kondisi Kerusakan Kolom akibat Simulasi Gaya Gempabumi arah X (Sumber: Hasil Analisis)

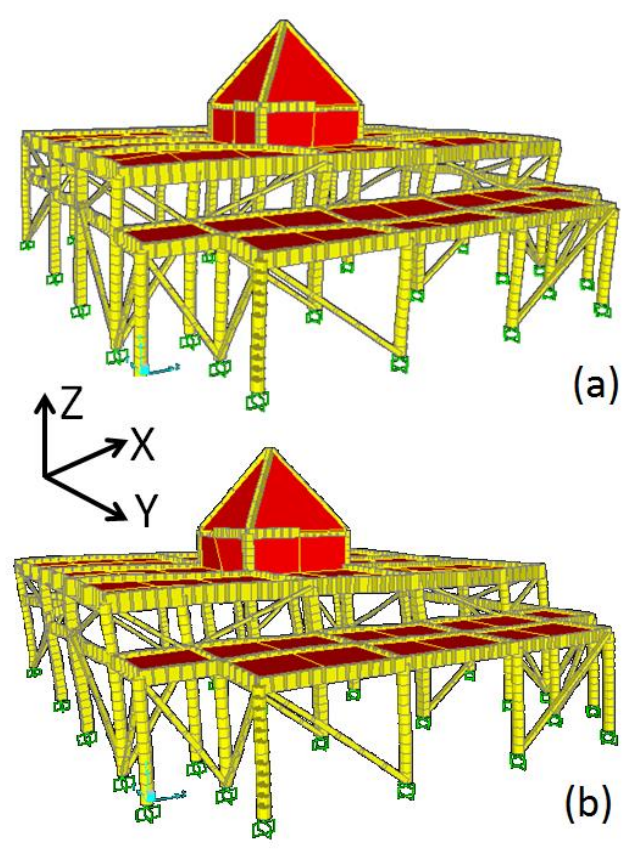

Gambar 9. Penambahan Bracing di antara Kolom Bangunan (Sumber: Hasil Analisis) 


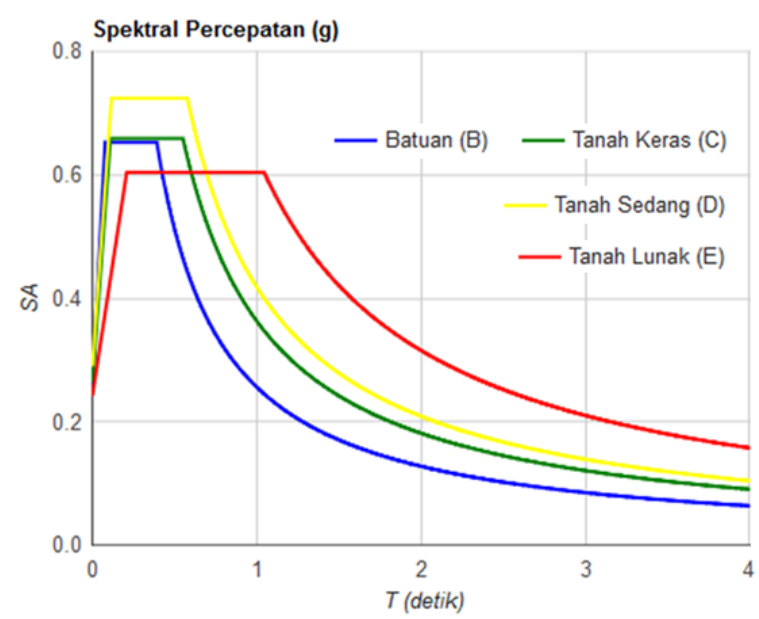

Gambar 10. Desain Spektrum di Lokasi Bangunan (Sumber: Kemen PUPR, 2011)

\subsection{Pembahasan}

Agar diketahui pada saat intensitas gempabumi berapa bangunan mulai rusak, maka dilakukan kajian sebagai berikut. Berdasarkan desain spectrum yang dikeluarkan oleh Kementerian Pekerjaan Umum dan Perumahan Rakyat, maka desain spektrum di lokasi bangunan ditunjukkan pada Gambar 9 . Dari gambar tersebut, maka diasumsikan klasifikasi tanah adalah sedang (D), karena berada di tanah dengan kemiringan landai. Percepatan gempa di permukaan tanah adalah $0,29 \mathrm{~g}$. Sedangkan spektral percepatan pada $T 1$ $=0,52$ detik adalah $0,724 \mathrm{~g}$.

Kolom mulai terlampaui kapasitasnya saat gedung mengalami percepatan sebesar $0,2 g$. Jika dibandingkan dengan spektral percepatan desain (Gambar 10), maka nilai ini adalah $0,2 / 0,724$ atau $1 / 3,6$ dari desain. Hasil ini menunjukkan, bangunan seharusnya mempunyai daktilitas 3,6 agar seandainya gaya gempa terlampui, maka masih ada kekuatan struktur mencegah terjadinya keruntuhan. Akan tetapi, persyaratan daktilitas bangunan belum terpenuhi pada bangunan ini, karena:

- Tulangan bukan ulir

- Jarak sengkang tidak rapat di daerah momen terbesar

- Adanya short column mechanism karena ada pengaruh kekuatan tembok

Dengan kenyataan yang ada, diasumsikan bangunan hanya mampu sampai percepatan spectral $=0,2 g$. Berdasarkan grafik percepatan spectral, maka percepatan puncak tanah saat terjadi percepatan spectral $0,2 \mathrm{~g}$ adalah $0,29 \mathrm{x}$ $0,2 / 0,724=0,08 g$ atau sekitar MMI V $(0,039-$ $0,092 g$ ).

Karena melihat rendahnya kapasitas bangunan di atas, maka sebuah usulan untuk peningkatan kekuatan bangunan ini dalam menahan beban gempa akan dikaji. Metode perbaikan yang diusulkan adalah: penambahan rangka bracing, hal ini dimungkinkan karena tersedianya ruang kosong di antara dua kolom. Dengan adanya rangka bracing ini diharapkan beban lateral gempabumi di kolom dapat dibagi bersama dengan rangka bracing. Sedangkan berat sendiri struktur tetap didukung oleh kolom.

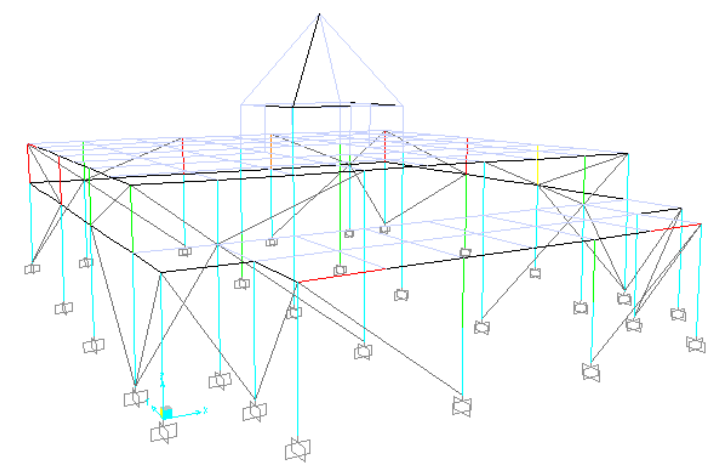

Gambar 11. Kondisi Kerusakan Kolom setelah ditambah Bracing akibat Simulasi Gaya Gempabumi arah X (Sumber: Hasil Analisis)

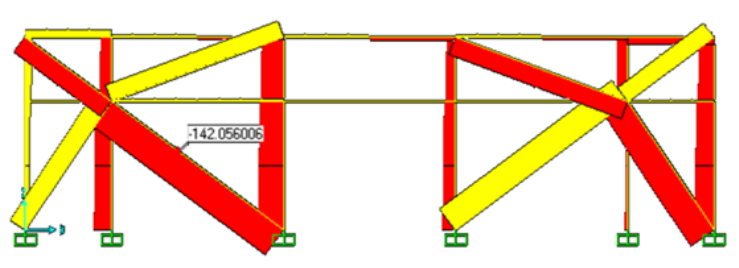

Gambar 12. Gaya Aksial Maksimum pada Bracing (Sumber: Hasil Analisis)

$$
\begin{aligned}
& \text { Sebagai batang diagonal bracing, } \\
& \text { diasumsikan mempunyai dimensi dan } \\
& \text { kekuatannya adalah: }
\end{aligned}
$$

- Bracing 1 (dipasang pada bentang panjang): Baja Hollow Persegi: Sisi $=12 \mathrm{~cm}$ tebal 7 $\mathrm{mm}$, Luas penampang $=16,31 \mathrm{~cm} 2$, Kuat Tarik $=2400 \times 16,31=39$ ton $=390 \mathrm{kN}$

- Bracing 2 (dipasang pada bentang pendek): Baja Hollow Persegi: Sisi $=10 \mathrm{~cm}$ tebal 6 $\mathrm{mm}$, Luas penampang $=11,64 \mathrm{~cm} 2$, Kuat Tarik $=2400 \times 11,64=28$ ton $=280 \mathrm{kN}$

Beban gempa juga disimulasikan pada model dengan bracing di atas. Percepatan spektral sebesar $0,4 \mathrm{~g}$ diaplikasikan pada arah $X$. Hasilnya menunjukkan bahwa pada saat percepatan spektral sebesar $0,4 \mathrm{~g}$ diaplikasikan, maka kolom-kolom pada struktur masih belum rusak (Gambar 11). Dalam hal ini penambahan bracing dapat meningkatkan kekuatan struktur sampai 4 kalinya. Gaya aksial maksimum pada 
bracing (pada sisi belakang gedung) adalah 142 kN (Gambar 12). Nilai ini lebih kecil dari kapasitas bracing yaitu $390 \mathrm{kN}$.

Dengan adanya bracing, maka bangunan ini dapat menerima gaya gempa lebih besar (sampai 4 kali bangunan tanpa bracing). Gaya aksial yang bekerja pada bresing baja ukuran 12 x $12 \mathrm{~cm}$ yang dipasang pada sebagian perimeter bangunan tidak melampaui batas kapasitas bracing-nya. Dalam pengembangannya, dapat juga diaplikasikan rangka bracing yang bersifat ductile atau bracing dengan peredam, agar perilaku gedung saat gempa menjadi lebih baik:

- Tidak terjadi peningkatan kekakuan yang signifikan

- Sifat meredam energi gempa lebih baik

- Metode pelaksanaan penerapan bresing ini pada bangunan ini memerlukan studi yang lebih lanjut.

\section{KESIMPULAN}

Berdasarkan hasil kajian di atas, maka disimpulkan beberapa hal sebagai berikut:

a. Bangunan yang dikaji ini, Masjid Kerandangan, mulai rusak pada intensitas gempa sekitar MMI V $(0,039-0,092 \mathrm{~g})$

b. Kapasitas yang rendah ini berhubungan dengan kuat tekan beton yang rendah (maksimum 10,5 Mpa) dan rasio tulangan yang kecil $(0,013$; mendekati nilai minimum rasio tulangan kolom)

c. Deformasi lateral juga menyebabkan kerusakan komponen non struktur yaitu pada tembok bata dan kaca, yang berpotensi membahayakan keselamatan manusia.

d. Direkomendasikan untuk memperbaiki bangunan ini dengan memasang bracing baja

e. Pemasangan bracing di bangunan ini dapat meningkatkan kemampuan bangunan dalam menerima beban gempa sampai 4 kalinya

\section{PERSANTUNAN}

Ucapan terima kasih disampaikan kepada Direktur Pusat Teknologi Reduksi Risiko Bencana - TPSA - BPPT, yang telah menyediakan sumber dana untuk terselenggaranya kegiatan kajian ini.

\section{DAFTAR PUSTAKA}

BMKG. 2018. Ulasan Guncangan Tanah Akibat Gempa Lombok Timur 05 Agustus 2018, [terhubung berkala]. https://www.bmkg.go.id/seismologiteknik/ulasan-guncangantanah.bmkg?p=ulasan-guncangan-tanahakibat-gempa-lombok-timur-05-agustus2018\&lang=ID.

Fajar Aribisma, F., Raka, I.G.P. dan Tavio. 2015. Evaluasi Gedung MNC Tower Menggunakan SNI 03-1726-2012 dengan Metode Pushover Analysis, Jurnal Teknik ITS, 4(1): 2301-9271 Print. ISSN: 23373539 .

Setiawan, J., dan I. Imran. 2014. Evaluasi Geser Dasar Minimum pada SNI 17262012, Jurnal Teknik Sipil, 10(2): 92-203.

Kementerian PUPR. 2011. Desain Spektra Indonesia [terhubung berkala]. http://puskim.pu.go.id/Aplikasi/desain_spekt ra_indonesia_2011/.

Kementerian PUPR. 2015. Pedoman Pengukuran Ketebalan Selimut Beton dengan Covermeter Elektromagnetik, Surat Edaran Menteri Pekerjaan Umum dan Perumahan Rakyat Nomor : 21/SE/M/2015.

Rizky, M., A. Kurniawandy and Z. Djauhari. 2015. Evaluasi Rangka Beton Bertulang dengan Dinding Geser Menggunakan FEMA 310, JOM FTEKNIK, 2(2).

Standar Nasional Indonesia. 2012. Tatacara Perencanaan Ketahanan Gempa untuk Struktur Bangunan Gedung dan Non Gedung, SNI 1726:2012, Badan Standardisasi Nasional.

Standar Nasional Indonesia. 2013. Beban Minimum untuk Perancangan Gedung dan Struktur Lain, SNI 1727:2013, Badan Standardisasi Nasional.

Standar Nasional Indonesia. 2013. Persyaratan Beton Struktural untuk Bangunan Gedung, SNI 2847:2013, Badan Standardisasi Nasiona 